\title{
Engaging health professionals and patients in the medical field: role of radiological protection culture and informed consent practices
}

\author{
C. Schieber ${ }^{1, *}$, C. Pölzl-Viol ${ }^{2}$, M.-C. Cantone ${ }^{3}$, N. Železnik ${ }^{4}$, S. Economides ${ }^{5}$, R. Gschwind ${ }^{6}$, \\ B. Abelshausen ${ }^{7}$, D. Savu ${ }^{8}$, S. Lafage ${ }^{1}$, L. Liutsko ${ }^{9}$, S. Charron ${ }^{10}$, C. Turcanu ${ }^{7}$ and R. Geysmans ${ }^{7}$ \\ ${ }^{1}$ CEPN-Nuclear Protection Evaluation Center, Fontenay-aux-Roses, France. \\ 2 BfS-Federal Office for Radiation Protection, Willy-Brandt-Straße 5, Salzgitter, Germany. \\ ${ }^{3}$ University of Milan, Via Pascal, 36, 20133 Milan, Italy. \\ ${ }^{4}$ Milan Vidmar Electric Power Research Institute, Hajdrihova 2, 1000 Ljubljana, Slovenia. \\ ${ }^{5}$ EEAE-Greek Atomic Energy Commission, 15310 Agia Paraskevi-Attiki, Greece. \\ ${ }^{6}$ Université Franche Comté, Laboratoire Chrono-environnement, Montbéliard, France. \\ 7 SCK CEN-Belgian Nuclear Research Centre, Boeretang 200, B-2400 Mol, Belgium. \\ ${ }^{8}$ National Institute for R\&D in Physics and Nuclear Engineering, Bucharest, Romania. \\ ${ }^{9}$ ISGlobal, Dr. Aiguader, 88, 08003 Barcelona, Spain. \\ ${ }^{10}$ IRSN - Institut de Radioprotection et de Sûreté Nucléaire, Fontenay-aux-Roses, France.
}

\begin{abstract}
In medical exposure situations, the significant role of and the need to improve the benefit/risk dialogue between health professionals, patients and other stakeholders are well recognized. This paper analyses stakeholder engagement processes in various medical applications of ionising radiation. It addresses the role and potential benefit of radiological protection (RP) culture for health professionals and the issues associated with the practical implementation of informed consent processes. The paper highlights the need to develop RP culture among health professionals to facilitate dialogue between practitioners and patients and to foster the implementation of the principles of radiological protection. It argues that patients' participation can be enhanced by creating spaces and opportunities for dialogue between patients and the relevant medical professionals, both before the implementation of medical procedures using ionising radiation, particularly at the moment of referral, as well as after these procedures. Risk communication training for medical professionals and their closer collaboration on this topic may enhance the dialogue with patients.
\end{abstract}

Keywords: medical exposures / stakeholder engagement / patients' engagement / radiological protection culture / ENGAGE

\section{Introduction}

The growing use of ionising radiation in the medical field for both diagnostic and therapeutic purposes over the past years gives rise to an increase of annual doses to the population originating from medical procedures, as well as a higher frequency of exposure situations for the health professionals (Vano, 2011; Smith-Bindman et al., 2012; Bourguignon et al., 2017; Dreuil and Etard, 2017; Ribeiro et al., 2019). In this context, significant efforts have been made to identify and promote methods to enhance the implementation of radiological protection (RP) for patients and health professionals, with

*Corresponding author: schieber@cepn.asso.fr notably the elaboration of numerous guidelines from national and international organizations (e.g. ICRP, 2007a, 2007b; ESR, 2011; IAEA, 2018).

A wide range of stakeholders can play different roles in the application of the key RP principles of justification of exposures, optimization of radiological protection and limitation of individual exposures, either individually, or being involved together in medical practices (Lefebvre et al., 2008). These stakeholders include, among others: medical professionals directly involved in procedures using ionising radiation (e.g. radiology, radiotherapy, nuclear medicine, interventional procedures, dentistry, etc.); referrers, nurses and other medical professionals who are not directly involved, but may be professionally exposed or interact with patients; patients, caregivers, patient representatives; hospital management staff; 
Table 1. Case studies on radiological protection (RP) culture and stakeholder engagement of medical professionals.

\begin{tabular}{ll}
\hline Case study & Main findings \\
\hline $\begin{array}{l}\text { 1. Implementation of a new RP training } \\
\text { course for 3rd year students in nurse } \\
\text { school (Montbéliard, France) }\end{array}$ & $\begin{array}{l}\text { Deficit of initial RP training for nurses. } \\
\text { Key topics to be taught are: radiations and associated health effects; use of ionising radiations } \\
\text { in medicine; associated exposure levels (patients and workers); means of protection; concrete } \\
\text { examples. }\end{array}$ \\
$\begin{array}{l}\text { Access to additional resources is needed (to be provided } \text { e.g. via internet, by professional } \\
\text { nurses associations or RP societies) }\end{array}$ \\
$\begin{array}{l}\text { Additional RP training resulted in: more realistic perception of risk associated with medical } \\
\text { physicians participating in }\end{array}$ \\
$\begin{array}{l}\text { fluoroscopically guided procedures } \\
\text { (Greece) }\end{array}$ \\
$\begin{array}{l}\text { exposures; use of risk as additional criterion in decision making; familiarization with } \\
\text { optimization tools; improved communication with RPEs and MPEs in hospitals. }\end{array}$ \\
$\begin{array}{l}\text { Feedback from participants used to optimise course's design and organisation. } \\
\text { risk of accidental exposures in } \\
\text { radiotherapy (Italy) }\end{array}$ & $\begin{array}{l}\text { RP culture leads to increased awareness of risk and benefits in radiotherapy; it can support } \\
\text { sharing experiences and learning from errors. }\end{array}$ \\
RP culture can help create or increase openness, mutual trust, and participation in a \\
transparent, inclusive and collaborative environment.
\end{tabular}

4. Experience from nurse-practitioners (Belgium)

5. Stakeholders' role in medical exposures of pregnant women (Greece)

6. Stakeholders' role in radiological protection aspects in relation to interventional procedures (Italy)
Low awareness among nurse-practitioners on Informed Consent, and confusion about who is responsible (nurse-practitioners or doctors?)

Participation and communication used interchangeably.

Stakeholder participation considered on a short time frame; nurse practitioners have no opportunity for participation.

Senior managers and heads of radiology departments showed a satisfactory level of awareness regarding the particularities of medical exposures of pregnant women. This is encouraging, as they have to play a key role as far as the effective engagement of the medical staff is concerned. Motivators of stakeholders (referral physicians, radiology physicians, technologists) for their engagement: need to comply with legislative requirement and commitment to safety.

Benefits of engagement: prevention of unjustified exposures, optimization of doses received by unborn children; prevention of inadvertent exposures.

Challenges for stakeholder engagement: lack of awareness about risks associated to exposure of unborn children to ionising radiation; and lack of a safety culture.

Recognized low collaboration between the professional figures involved in the use of ionising radiation.

Vocational training mainly centred on scientific and technical aspects; however, it is also an opportunity to exchange experiences, concerns and points of view in practice, and to start a true collaborative approach, in which each part can integrate knowledge and competence. In general, no attention dedicated to patients' involvement in decision processes; the patient is seen as care receiver and attention dedicated to technical aspects of radiological protection for patient care. manufacturers of medical equipment; authorities; medical societies and associations at national and international level; radiological protection associations. The Bonn Call-for-Action to Improve Radiation Protection in Medicine (IAEA and WHO, 2012), advocates for "closer co-operation on radiation protection between different disciplines of medical radiation applications as well as between different areas of radiation protection overall, including professional societies and patient association" as one of the key actions to strengthen radiation protection in medicine. It is also argued that there is a need to improve the benefit/risk-dialogue between health professionals, patients and other stakeholders regarding medical exposures to ionising radiation (IAEA and WHO, 2012; WHO, 2016; Ribeiro et al., 2019).

Given this heightened recognition of the need for stakeholder participation, the ENGAGE project (Turcanu et al., 2019, 2020) analysed requirements, guidelines and practices of stakeholder engagement in the medical field through various case studies covering a wide range of medical applications of ionising radiation in different countries. The analysis of prescriptions was conducted on the basis of document analysis and interviews with representatives of international organisations (Železnik et al., 2019a, 2019b). Attention was directed, among others, towards rationales for involvement and the forms of participation prescribed or practiced.

Case studies addressed: a) the involvement of medical professionals in the implementation of radiological protection principles, including the specific role of radiological protection culture (RP culture) to strengthen this engagement (Tab. 1); and $b$ ) how the informed consent principle for patients is understood and implemented regarding medical exposures to ionising radiation (Tab. 2). Data were collected through document analysis, interviews, facilitated discussions and one 
Table 2. Case studies on communication with, and engagement of patients.

\begin{tabular}{ll}
\hline Case study & Main findings \\
\hline 1. Justification, optimization, education & Communication with patients perceived by medical staff as beneficial, as it can improve \\
and training at the Institute of Oncology & $\begin{array}{l}\text { medical treatment, reduce patients' concerns and doses to patients. } \\
\text { Information about justification and optimization of IR use should be updated/included in } \\
\text { (Slovenia) }\end{array}$ \\
& $\begin{array}{l}\text { printed information material and websites. } \\
\text { Explanations provided to patients limited due to concern not to frighten people and lack of time. }\end{array}$
\end{tabular}

2. Informed consent among cancer patients undergoing radiotherapy (Romania, $\mathrm{N}=86$ )

3. Justification, optimization of ionising radiation use and stakeholder engagement in paediatric CT-scan (Spain)

4. Justification, optimization of ionising radiation use and stakeholder engagement in dental private clinics (Spain)

5. Risk communication in curricula for medical professionals (International level)
Consent is requested two days before the procedure.

Information about the risks and benefits of the procedure, possible alternatives and general information are considered important by the patients; $10 \%$ find technical details about procedure less important.

Most patients consider that information received satisfied their needs; half of respondents found information received di to understand; $40 \%$ recommended that information is given both orally and in writing.

One in two patients consider that information should be given some days before therapy; others think this should be given immediately before the procedure.

General lack of time and human resources in hospitals leads to less time devoted to communication with patients.

Patients are informed about risks from radiation exposure mainly by the leading doctor; however, some wished to reconfirm with hospital RP professionals.

Professional stakeholders argue for improving the basic knowledge among the general public on medical exposures and associated risks and benefits. Patients' and professional associations could help by posting more information in their web pages or blogs, with open and easy access.

No information, in view of informed consent, is provide before the exposure, and in some dental clinics no optimization of doses is applied.

Both professional stakeholders (dentists) and patients need to obtain more information about the use of IR in dental practices, to enable collaboration on decisions on IR use, justification and optimization.

Professionals of dental clinics need additional education to update their knowledge on RP and new changes in law and its application in practice.

Risk communication is seldom included in the training of medical specialists (radiology, radiation therapy, nuclear medicine).

The gap between radiation protection activities at academic level and requirements at vocational level does not support stakeholder engagement activities and a penetration of the radiation protection community with the consciousness of the importance of risk communication skills in other areas than emergency management.

The radiation protection community should encourage good risk communication approaches. Guidance for radiation risk communication should be provided for and co-developed with medical expert associations. survey. It has to be noticed that the doses to patients and staff vary significantly between the medical procedures addressed in the various case studies, and attention to stakeholder engagement may also vary accordingly. Full case studies are presented in Barazza et al. (2019) and Cantone et al. (2019).

This paper presents some of the main findings of the ENGAGE Project regarding: 1) the role and potential benefit of RP culture for health professionals; 2) the processes to build and transmit RP culture, adapted to the specificities of different types of health professionals; 3) how the expectations for communication with patients and their engagement through informed consent are prescribed and translated in practice and what the related challenges and opportunities are. The engagement of health professionals has also been addressed within the ENGAGE Project, but is not presented in this paper. Findings from ENGAGE research were discussed and recommendations were co-developed with a panel of stakeholders during two workshops in 2019 in Athens (Schieber and Schneider, 2019) and Bratislava (Duranova et al., 2019).

\section{Developing radiological protection culture for medical professionals}

Radiological protection culture is a concept of composite nature, characterized by a set of perceptions, values, attitudes, beliefs and expectations related to radiation risk; an assembly of knowledge, know-how, skills, experience, and practices related to radiological protection (RP); and a dynamic development process based on multi-stakeholders' interactions (IRPA, 2014). 
The key issues addressed in the ENGAGE Project regarding RP culture in the medical field were related to its role to facilitate the dialogue between practitioners and patients regarding radiation risk in the framework of the informed consent processes and to foster the implementation of the principles of justification and optimisation of radiological protection for patient exposures. Analysis focused on the role and development of RP culture for health professionals, with a particular attention to: 1) health professionals who are not directly involved in medical exposures but may be occupationally exposed and/or interact with patients; the main case study concerned the nurses (case study 1, Tab. 1), with investigations of the content of their initial training and education; 2) health professionals directly involved in procedures using ionising radiation, with the specific cases of physicians involved in fluoroscopy guided procedures (e.g. interventional radiology or cardiology, urology, gastroenterology) and professionals implicated in radiotherapy (case studies 2 and 3, Tab. 1).

\subsection{Objectives and elements of RP culture for health professionals}

The case studies showed that the objectives for developing RP culture vary according to the specialty of the health professionals, the direct or indirect nature of their involvement in medical procedure giving rise to exposures to ionising radiation, as well as their roles and responsibilities regarding the implementation of RP principles.

For instance, nurses are not directly involved in the use of ionising radiations for medical purposes. Therefore, the aim of developing RP culture for them is first to raise their awareness of exposure situations encountered at the workplace (case study 1, Tab. 1). This should increase their capacity to take self-protection measures, as well as to understand the relevant RP protocols for the patients. Additionally, as these professionals are in direct contact with patients, they should also be able to provide advice and explanations to patients having concerns regarding exposure to ionising radiation, in complement to those provided by medical practitioners. Raising radiological risk awareness for nurses can be achieved through an initial training course combining presentations of elements of knowledge on radiations and associated health effects, overview of the use of ionising radiations in the medical field, associated exposure levels, and means of protection (for patients and staff). It has been observed in the case studies that it might be difficult to introduce many hours of training on a new topic in education programmes already set up by the schools. It becomes then essential to provide the students with the possibility to have access to further information (e.g. links to websites, identification of RP Expert in a hospital).

The aim of RP culture is different for medical professionals directly involved in procedures involving the use of ionising radiation, such as fluoroscopy guided procedures (case study 2 , Tab. 1), particularly those that may lead to high exposures for patients and participating staff. For these professionals, the aim of RP culture is to improve their practice by integrating radiological risk as an additional criterion in their decisionmaking process. The development of RP culture should increase their understanding of processes to optimise patients' radiological protection, and improve their interactions with Medical Physics Experts (MPEs) and Radiation Protection Experts (RPEs) in the elaboration and implementation of these processes. These professionals have usually received an initial training on radiological protection during their first year of study, as well as some elements during the undergraduate/post graduate studies for their specialty. At this stage, the information provided usually covers theoretical aspects of radiological protection and rarely practical aspects. Furthermore, the techniques involving the use of ionising radiation are evolving quite quickly. The development of RP culture for these professionals relies thus on its integration into the continuous education and training (or periodical update of knowledge), where both theoretical and practical aspects of radiological protection should be developed.

The third type of medical professionals studied are those involved in procedures were a significant attention has to be paid to avoid accidental / incidental exposures of patients, such as radiotherapy (RT) (case study 3 , Tab. 1). In that case, a main aim of RP culture is the development of a structured approach to identify and analyse adverse events, in order to prevent critical situations (Schuller et al., 2017). Target stakeholders include medical physicists, radiotherapists and other staff that may be involved in these procedures. The main components of RP culture include knowledge of the roles and responsibilities of each actor in the treatment processes, awareness about the aspects of decision-making processes that can be at the origin of an incident/accident, and the quality control of the entire process. Not all staff involved in radiotherapy procedures have the same level of knowledge in radiological protection as the radiotherapist or the medical physicist. Therefore, for these staff members, the organisational and management aspects should be complemented with basic knowledge regarding radiation risks associated with radiotherapy treatments.

\subsection{Processes to build and disseminate RP culture for health professionals}

It results from the above that education and training (E\&T) on radiological protection is one of the key methods to strengthen RP culture of medical professionals. Radiological protection should be included in the initial training of professionals, but also integrated into a continuous E\&T programme. As noted also by Ploussi and Efstathopoulos (2016), this continuity is essential to maintain the awareness of radiological risk, and to integrate new aspects of radiological protection reflecting the evolution in the uses of ionising radiation in the medical field.

In the development of E\&T programmes, medical professional associations and national radiological protection authorities can play an important role, for example through the organization and/or participation to seminars of the relevant medical speciality, or the joint elaboration of training materials, covering both theoretical and practical aspects of radiological protection.

The case studies revealed also that radiological protection authorities can use inspections to foster the awareness of medical professionals on the importance of radiological protection. As shown by a case study in Greece (case study 
2, Tab. 1), definition of appropriate indicators for the evaluation of the RP culture, may be a useful tool for systematically monitoring and evaluating the radiological protection culture of health professionals during on-site inspections.

Finally, some aspects of work management or work organization have also been identified as key elements fostering the integration of RP issues on a day-to-day basis in the medical procedures. For example:

- the internal evaluation of RP practices by the RP Expert. These evaluations, to be performed in close cooperation with the medical professionals, favour the creation of venues where dialogue can take place and RP issues can be addressed;

- the integration of RP into Quality Assurance programmes (clinical audits). These are important organisational elements in which procedures to be applied for the provision of RP training, information dissemination and the evaluation of practices should be integrated in a formal way (see e.g. the handbook developed by IAEA, 2010).

\section{From informed consent to patient engagement}

In recent years, national and international professional organisations concerned with the medical use of ionising radiation, as well as patients' associations promoted a new paradigm in medical healthcare, centred on patient's needs, values and preferences (e.g. EPF, 2015; ESR, 2017; Kemp et al., 2017). In the medical field, in general, and in relation to the use of ionising radiation, in particular, this involves, among others, enhanced communication with patients and care givers, providing for opportunities to participate in decision-making, and the implementation of informed consent (IAEA and WHO, 2012; EPF, 2015; WHO, 2016). Their interconnection is pointed out for instance by the study of Ribeiro et al. (2019) which concludes that "adequate and accurate information [for patients] is crucial to ensure the principle of informed consent is present".

According to the EU Basic Safety Standards (Euratom BSS, 2013), medical practitioners have the clinical responsibility to give information about the risks of radiation-induced effects of diagnostic and therapeutic procedures to the patients and other involved individuals "as appropriate" and obtain their consent for conducting a medical procedure involving the exposure to ionising radiation (EU BSS, Chapter II, Article 4). However, the EU BSS grants a certain amount of freedom to the Member States by stating that "adequate" information relating to the benefits and risks associated with the radiation dose from the medical exposure shall be provided "wherever practicable" (EU BSS, Art. 57 (d)). Consent entails agreement of the patient with the proposed procedure based on one-wayinformation on its risks and likely benefits (Euratom BSS, 2013), making sure that the patient understands properly the "nature and the consequences of what is proposed" (ICRP, 2007a). However, there are also views that point out the need for dialogue (IAEA and WHO, 2012) or argue that informed consent should be conceived as a process between the patient and health care provider, facilitating a more active engagement of patients and caregivers in decision-making related to the treatment, at least in some contexts, e.g. chronical diseases, paediatric radiation oncology (Olson et al., 2012; European Patients' Forum, 2015).

Past studies highlighted a number of challenges for the transposition of informed consent in practice, notably in the specific context of medical exposures to ionising radiation. These include, among others, lack of time and high workload of medical professionals, lack of specific guidance on communication with patients and on patient engagement, low awareness about ionising radiation among patients, lack of appropriate documentation of consent, and unclear responsibilities in the consent process (O’Dwyer et al., 2003; Akkad et al., 2006; Colyer, 2007; Brassil and Limerick, 2015; Friedrich-Nel and Munro, 2015). These studies also made suggestions for improving the consent process, such as promoting active cooperation among professionals, standardized templates for communication, use of various communication tools, or a two-stage consent process (first patients receive information, then they confirm their consent prior to the procedure).

Several professional associations (e.g. UK's Royal College of Radiologists) have published standards concerning patients' informed consent, recognizing the importance of fully involving patients in decisions and communicating information effectively (Purificacion et al., 2016; Kasraie et al., 2018; ESR and EFRS, 2019). Tools were also identified that may support patients' and caregivers' participation in decisionmaking (see Stacey et al., 2017 for a review).

Starting from the idea that patients' involvement in decision-making is the underlying basis for informed consent, the ENGAGE project analysed the prescriptions for communication with patients and patients' involvement in decision making, including informed consent, and their practical implementation. For the latter, a number of case studies were conducted in different countries (cases 4-6, Tab. 1; case studies listed in Tab. 2).

\subsection{Prescriptions for patients' engagement}

In recommendations from international organisations (ICRP 2007a, 2007b; IAEA and WHO, 2012) different approaches are recognized regarding the patients' informed consent. In particular, the content and detail of information considered relevant for patients, family and friends are seen to vary depending on the level and type of exposure, the medical procedure and the related potential risks. In relation to patients' engagement, two aspects are emphasized: i) the benefit-risk dialogues in radiology and radiotherapy; and ii) the need to improve risk communication by developing adequate messages and approaches towards patients and the public and the communication skills of medical professionals and Radiation Protection Experts (Železnik et al., 2019b).

In national radiological protection regulation (Tab. 3), for instance in Slovenia and Italy, the responsibility of practitioners, involved either in prescription or administration of medical exposures, is mostly seen as providing information to patients. This can of course be a stepping stone to a dialogue, but dialogue is not explicitly prescribed. Patients as stakeholders are still seen as a subject of concern needing protection and having the right to information, and thus the engagement of patients is mostly "restricted" to having the autonomy of 
Table 3. National legislation analysed (Železnik et al., 2019b).

\begin{tabular}{|c|c|}
\hline Country & Regulatory document \\
\hline Germany & $\begin{array}{l}\text { 1) Gesetz zur Verbesserung der Rechte von Patientinnen und Patienten, by } 20 \text { th February } 2013 \text { ("Act to improve rights } \\
\text { for patients"). 2) Gesetz zur Neuordnung des Rechts zum Schutz vor der schädlichen Wirkung ionisierender Strahlung. } \\
\text { National legislation, Germany ("New Radiation Protection Act") by } 27 \text { th June 2017; }\end{array}$ \\
\hline Italy & $\begin{array}{l}\text { 1) D. Lgs. } 187 / 2000 \text {. Legislative Decree } 187 / 2000 \text {. Implementation of Directive } 97 / 43 \text { EURATOM on health protection } \\
\text { of persons against the dangers of ionising radiation via medical exposures. 2) ISISTAN 15/41, } 2015 \text { Operative } \\
\text { indications for the optimization of radioprotection in interventional radiology procedures; }\end{array}$ \\
\hline
\end{tabular}

Slovenia Ionising radiation protection and nuclear safety act (ZVISJV- 1), Off. Gaz. 76/2017-Atomic Act

Spain Royal decree project on justification and optimization of the use of ionising radiations for the radiological protection of people on the occasion of medical expositions, 7/02/2018.

giving informed consent (or not). Other legal documents, not specific to radiological protection, provide for more interactive approaches stating, for instance, that the "treating physician and patient shall cooperate for the application of the treatment" ("The Act to Improve the Rights of Patients" in Germany).

The rationales underlying the aforementioned requirements are twofold. On the one hand, the emphasis on patients' and caregivers' right for information clearly reflects first and foremost a normative rationale. On the other hand, informing the patients in order to obtain informed consent also pertains to an instrumental motivation. The requirement to ensure that patients and caregivers understand the consequences of what is proposed is thus essential for a meaningful informed consent process.

\subsection{Informed consent in practice}

The case studies revealed that in many cases, health professionals, while introducing the use of ionising radiations to patients in relation to justification, tend to limit the extent of their explanation. This can be due to several reasons, such as not wanting to scare patients, lacking time for detailed explanations, or having difficulties to deal with the complexity of deciding what and how to communicate about risk and benefits (case studies 1, 3 and 4 in Tab. 2). Moreover, the perceived low level of patients' awareness on radiological protection, is sometimes considered as a motivation for giving less priority to providing detailed information to patients (case 6, Tab. 1).

Other medical personal could therefore provide support in establishing improved communication with the patients, for instance nurses, general practitioners (who often act as referrers), or radiation physicists (as suggested for instance in case study 3, Tab. 2). A case study in Belgium (case study 4, Tab. 1) shows, however, that nurses may have currently limited or no opportunity to do so in their daily practice and will most often refer patients to medical practitioners for advice and information, as well as for informed consent. Developing RP culture for medical staff that is not directly involved in medical procedures using ionising radiation, but that may interact with patients, as recommended in the previous section, has therefore the additional benefit of potentially enhancing communication with, and engagement of, patients.

Some cases suggest that little or no attention is dedicated to patients' involvement in decision making processes (case study 6, Tab. 1; case study 4, Tab. 2). A case study on interventional procedures in Italy indicates that the patient is seen only as the care receiver and attention is dedicated to technical aspects of radiological protection regarding the respective procedure.

A case study among cancer patients undergoing radiotherapy (case study 2, Tab. 2) suggests that patients consider that it is important to receive information about the risks and benefits of the procedure, the possible alternatives, general information about the procedure, and even technical details about the procedure. Most respondents stated that information provided satisfied their needs to a large or very large extent, regarding risks of the procedure $(83 \%)$, benefits of the procedure $(90 \%)$, possible alternatives $(78 \%)$, general information $(85 \%)$, and technical details (74\%). However, half of the respondents found the information received about ionising radiation was difficult or very difficult to understand. $60 \%$ of respondents considered that information should be given some days before therapy, while the others think that the information should be given immediately before the procedure. $40 \%$ of the respondents recommend that information should be given both orally and in writing, while others suggested either oral or written information (preliminary results in Savu and Stroe, 2019).

\subsection{Enhancing communication with patients}

The case studies confirm previous research (Martin et al., 2013; Mangano et al., 2015; Purificacion et al., 2016) in showing that there is a crucial need to develop specific guidance facilitating the dialogue between patients and health professionals. However, radiological risk communication is seldom included as a topic in training programs for medical professionals (case study 5, Tab. 2). The physician-patient conversations, as well as patient education, are part of education in medical schools, but no special radiation risk communication skills are developed.

To answer this concern, a European communication campaign to promote the appropriate use of medical imaging has recently been launched by $\mathrm{HERCA}^{1}$ in 2019. The campaign stages a consultation situation between referrer and patient and sets out key questions the referrer should ask

${ }^{1}$ HERCA: Heads of European Radiological Protection Competent Authorities. 
when prescribing an imaging examination. It highlights the patient's interests, along with some simple reflections and arguments that can be put forward during the consultation.

The capability to involve patients in meaningful dialogues and decision-making processes for medical exposures is reinforced by raising patient awareness about the associated benefit and risk. Many actors have been identified as playing a key role in setting up processes to disseminate information towards public and patients, such as national health and radiological protection authorities (e.g. national campaign in Belgium $^{2}$ ), patients' organisations (e.g. elaboration of an information leaflet by a pluralist working group in France ${ }^{3}$, chaired by a French patients' association), international organisations (e.g. IAEA with the elaboration of resources for patient ${ }^{4}$ ) or medical professional associations (e.g. Image Gently Alliance ${ }^{5}$ or Image Wisely ${ }^{6}$ ).

\section{Conclusions}

The analysis confirmed the need to develop radiological protection culture among health professionals to facilitate the dialogue between practitioners and patients regarding radiation risk in the framework of the informed consent processes and to foster the implementation of the principles of justification and optimisation for medical exposures.

Results also emphasize the importance of integrating or reinforcing the radiological protection culture as part of medical practices for the health professionals who are directly involved in medical exposures. The development of RP culture for these professionals relies on its integration into the continuous education and training and the periodical update of knowledge.

Additionally, the results reinforce the need to establish actions to develop and promote RP culture for health professionals who are not directly involved in medical exposures, but may be occupationally exposed and/or interact with patients. This is of particular importance for general practitioners, who often act as referrers.

Perspectives for further research include the development of open access sources of information on radiological protection in the medical field to complete the initial training of the health professionals.

It was also shown that the lack of time, low risk awareness among public and patients regarding the use of ionising radiation in medical procedures, together with the absence of radiological risk communication training among health professionals, hinder a meaningful engagement of patients through informed consent processes. A graded approach is proposed in guidelines and practices, relating the level of engagement with the doses resulting from the medical procedures. Dialogue with patients regarding risk/benefits of medical procedures using ionising radiation could be enhanced by including topics about patients' involvement and risk

\footnotetext{
${ }^{2}$ https://www.pasderayonssansraisons.be/fr.

${ }^{3}$ https://www.irsn.fr/FR/connaissances/Sante/exposition-patientssante-radioprotection/radiologie-scanner/Pages/sommaire.aspx.

${ }^{4} \mathrm{https}$ ://www.iaea.org/resources/rpop/patients-and-public.

${ }^{5} \mathrm{https}: / /$ www.imagegently.org/.

${ }^{6} \mathrm{https}: / /$ www.imagewisely.org/.
}

communication in education and training programs of medical professionals; closer collaboration on these topics among medical professionals; and co-development of communication materials with medical professionals, patients' representatives and communication experts.

Finally, patients' participation can be broadened beyond a formal informed consent by transparent communication on hospitals' policies regarding patients' doses, (e.g. open information about average patients' doses for specific procedures, or quality certificates such as EuroSafe Imagining $\mathrm{Star}^{7}$ ), as well as by creating spaces and opportunities for dialogue between patients and the relevant medical professionals, both before the implementation of medical procedures using ionising radiation, particularly at the moment of referral, as well as after these procedures.

Acknowledgements. The work described in this paper was conducted within the ENGAGE project, which was part of the H2020 CONCERT project. This project received funding from the EURATOM research and training programme 2014-2018 under grant agreement No. 662287.

Funding was also received from Romanian Ministry of Research and Innovation (grant 64PCCDI/2017).

Disclaimer (Art. 29.5 GA). This publication reflects only the authors' view. Responsibility for the information and views expressed therein lies entirely with the authors. The European Commission is not responsible for any use that may be made of the information it contains.

\section{References}

Akkad A, Jackson C, Kenyon S, Dixon-Woods M, Taub N, Habiba M. 2006. Patients' perceptions of written consent: questionnaire study. BMJ 333(7567): 528.

Barraza F, Cardis E, Cantone M-C, Charron S, Doremus P, Duranova T, Economides S, Gschwind R, Lafage S, Liutsko L, Murith C, Schieber C, Schneider T. 2019. Final report on case studies, including recommendations and guidelines on building and enhancing radiation protection culture. CONCERT Deliverable D9.87.

Bourguignon M, Bérard P, Bertho JM, Farah J, Mercat C, Radioprotection Editorial Board. 2017. What's next in Radioprotection? Radioprotection 52(1): 21-28.

Brassil G, Limerick IE. 2015. Development of a valid consent policy for radiological imaging procedures in Irish (HSE) hospitals. ECR 2015.

Cantone MC, Pölzl-Viol C, Abelshausen B, Economides S, Liutsko L, Savu D, Schieber C, Železnik N, Zorko B. 2019. Report on venues, challenges, opportunities and recommendations for stakeholder engagement in the medical field. CONCERT Deliverable D9.89.

Colyer H. 2007. Informed consent for radiotherapy: Our responsibility. Radiography 13(3): 197-201.

Dreuil S, Etard C. 2017. Exposure of the French population to ionising radiations from medical diagnostic procedures in 2012 . Radioprotection 52(1): 45-49.

Duranova T, Turcanu C, Abelshausen B, Železnik N, Pölzl-Viol C, Schieber C. 2019. ENGAGE Final Workshop. CONCERT Deliverable D9.88.

EPF. 2015. EPF background brief: Patient empowerment. European Patients' Forum.

ESR. 2011. White paper on radiation protection by the European Society of Radiology. Insights Imaging 2: 357.

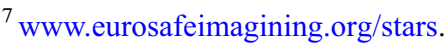


ESR. 2017. European Society of Radiology-ESR concept paper on value-based radiology. Insights Imaging 8(5): 447-454. https://doi.org/10.1007/s13244-017-0566-1.

ESR and EFRS. 2019. Patient safety in medical imaging: A joint paper of the European Society of Radiology (ESR) and the European Federation of Radiographer Societies (EFRS). Insights Imaging 10(45).

Euratom BSS. 2013. Council Directive 2013/59/EURATOM of 5 December 2013 laying down basic safety standards for protection against the dangers arising from exposure to ionising radiation. Off. J. Eur. Union.

Friedrich-Nel H, Munro L. 2015. Radiographers' opinion on patients' rights to informed consent: Results of an online survey. South Afr. Radiogr. 53(1): 27-32.

HERCA. 2019. European communication campaign to promote the appropriate use of medical imaging. Heads of European Radiological Protection Competent Authorities.

IAEA. 2010. Comprehensive clinical audits of diagnostic radiology practices: A tool for quality improvement. Quality assurance audit for diagnostic radiology improvement and learning (Quaadril). IAEA Human Health Series 4, Vienna.

IAEA. 2018. Radiation protection and safety in medical uses of ionising radiation. IAEA Safety Standards Series SSG-46. Vienna: IAEA.

IAEA and WHO. 2012. Bonn call for action - 10 actions to improve radiation protection in medicine in the next decade - Joint position statement by the IAEA and WHO. Available from https://www. who.int/ionising_radiation/medical_radiation_exposure/call-foraction/en/.

ICRP Publication 103. 2007a. The 2007 Recommendations of the International Commission on Radiological Protection. Ann. ICRP 37.

ICRP Publication 105. 2007b. Radiological protection in medicine. Ann. ICRP 37(6).

IRPA. 2014. IRPA Guiding principles for establishing a radiation protection culture. International Radiation Protection Association. Available from http://www.irpa.net/.

Kasraie N, Jordan J, Keup C, Westra S. 2018. Optimizing communication with parents on benefits and radiation risks in pediatric imaging. J. Am. Coll. Radiol. 15(5): 809-817.

Kemp JL, Mahoney MC, Mathews VP, Wintermark M, Yee J, Brown SD. 2017. Patient-centered radiology: Where are we, where do we want to be, and how do we get there? Radiology 285(2): 601-608. https://doi.org/0.1148/radiol.2017162056.

Lefebvre G, Kettunen E, Godet J-L, Olerud HM, Sánchez M, Trueb $\mathrm{Ph}$. 2008. Stakeholder involvement in medical practices. Report of the HERCA Working Group 5.

Mangano MD, Bennett SE, Gunn AJ, Sahani DV, Choy G. 2015. Creating a patient-centered radiology practice through the establishment of a diagnostic radiology consultation clinic. AJR Am. 205(1): 95-99.

Martin HM, Navne LE, Lipczak H. 2013. Involvement of patients with cancer in patient safety: A qualitative study of current practices, potentials and barriers. BMJ Qual. Saf. 22(10): 836.

O'Dwyer HM, Lyon SM, Fotheringham T, Lee MJ. 2003. Informed consent for interventional radiology procedures: A survey detailing current European practice. Cardiovasc. Intervent. Radiol. 26(5): 428-433.

Olson RA, Bobinski MA, Ho A, Goddard KJ. 2012. Oncologists' view of informed consent and shared decision making in paediatric radiation oncology. Radiother. Oncol. 102(2): 210213.

Ploussi A, Efstathopoulos EP. 2016. Importance of establishing radiation protection culture in Radiology Department. World J. Radiol. 8(2): 142-147.

Purificacion S, Brown E, Anne-Davis C, French J. 2016. Patient engagement in radiation therapy: The development of guidelines for current Canadian practices. Healthcare Manag. Forum 29(5): $187-195$.

Ribeiro A, Husson O, Drey N, Murray I, May K, Thurston J, Oyen W. 2019. Ionising radiation exposure from medical imaging-A review of patient's (un)awareness. Radiography. https://doi.org/ 10.1016/j.radi.2019.10.002.

Savu DI, Stroe D. 2019. Informed consent in medical use of radiation for cancer treatment in Romania. In: ENGAGE Final Workshop, 11-13 September, 2019. Available from www.engage-concert.eu.

Schieber C, Schneider T. 2019. Stakeholder Workshop: Development of radiological protection culture to support the governance of radiological risk. CONCERT Deliverable D9.84.

Schuller BW, Burns A, Ceilley EA, King A, LeTourneau J, Markovic A, Sterkel L, Taplin B, Wanner J, Albert JM. 2017. Failure mode and effects analysis: A community practice perspective. J. Appl. Clin. Med. Phys. 18(6): 258-267.

Smith-Bindman R, Miglioretti DL, Johnson E, Lee C, Heather Spencer Feigelson H, Flynn M, Greenlee RT, Kruger RL, Hornbrook MC, Roblin D, Solberg LI, Vanneman N, Weinmann S, Williams AE. 2012. Use of diagnostic imaging studies and associated radiation exposure for patients enrolled in large integrated health care systems, 1996-2010. JAMA 307(22): 2400-2409.

Stacey D, Légaré F, Lewis K, Barry MJ, Bennett CL, Eden KB, Holmes-Rovner M, Llewellyn-Thomas H, Lyddiatt A, Thomson R, Trevena L. 2017. Decision aids for people facing health treatment or screening decisions. Cochrane Database Syst. Rev. 4.

Turcanu C, Abelshausen B, Geysmans R, Van Oudheusden M, Meskens G, Schieber C, Schneider T, Železnik N, Pölzl- Viol C. 2019. Final report of the ENGAGE project. CONCERT Deliverable D9.94.

Turcanu C, Van Oudheusden M, Abelshausen B, Schieber C, Schneider T, Železnik N, Geysmans R, Duranova T, Perko T, Pölzl-Viol C. 2020. Stakeholder engagement in radiological protection: Developing theory, practice and guidelines. Radioprotection 55(HS2). https://doi.org/10.1051/radiopro/2020036.

Vano E. 2011. Global view on radiation protection in medicine. Rad. Prot. Dos. 147(1-2): 3-7.

WHO. 2016. Communicating radiation risks in paediatric imaging. Information to support healthcare discussions about benefit and risk. ISBN 978924151034 9, Geneva.

Železnik N, Turcanu C, Abelshausen B, Perko T, Meskens G, Geysmans R, Oudheusden M, Pölzl-Viol C, Cantone MC, Veronese I, Liutsko L. 2019a. Rationales and frameworks for stakeholder engagement in radiation protection. CONCERT Deliverable D9.85.

Železnik N, Turcanu C, Abelshausen B, Perko T, Meskens G, Geysmans R, Oudheusden M, Pölzl-Viol C, Cantone MC, Veronese I, Liutsko L, Zorko B. 2019b. Report on stakeholder engagement in radiation protection: transversal issues and specifics of different exposure contexts. CONCERT Deliverable D9.86.

Cite this article as: Schieber C, Pölzl-Viol C, Cantone M-C, Železnik N, Economides S, Gschwind R, Abelshausen B, Savu D, Lafage S, Liutsko L, Charron S, Turcanu C, Geysmans R. 2020. Engaging health professionals and patients in the medical field: role of radiological protection culture and informed consent practices. Radioprotection 55(HS2): S235-S242 